\title{
Controlling of Post-Harvest Losses of SelectedLeafy Vegetables and Green Chilies by Coating with Plant Mucilages
}

\author{
PAKC Wijerathne, VGG Chandrajith* and SB Navaratne \\ Department of food science and technology, University of Sri Jayewardenepura, Sri Lanka
}

Submission: May 22, 2018; Published: July 02, 2018

"Corresponding author: VGGChandrajith, Department of food science and technology, University of Sri Jayewardenepura, Sri Lanka, Tel: 0715236149; Email: gayanchandrajith1993@gmail.com

\begin{abstract}
The objective of the present study was to investigate the possible application of the edible grade plant mucilaginous of Neolestsea involucrate (Dawul Kurundu) (DK) over selected high respiratory leafy vegetable and green chilies as a thin coat.In this study five types of high respiratory vegetables names as Centellasiatica (Gotukola), Alternanthera sessilies (Mukunuvenna), Ipomoea aquatic (Kankun), Capsicum annum (Green chilies) and Allium ampeloprasum (leeks) were taken and coated with mucilaginous materials extracted from Dawul Kurudu (Neolestsea involucrate). The selected vegetables were coated with Dawul Kurudu and their keeping quality, weight loss, cumulative inedible percentage, colour measurement $\left(\mathrm{L}^{*} \mathrm{a}^{*} \mathrm{~b}^{*}\right)$, the total chlorophyll concentrations were determined and results were compared with the control sample. Green chilies could be kept for 22 days in open environment with very good organoleptic properties with the DK mucilage and the ripening process also had been delayed Gotulola and leeks with DK mucilage were able to keep 10 and 9 days respectively. The weight losses of the Green chilies, Leeks, and Gotukola were reduce by considerable amount with the DK mucilage and they were remained with better organoleptic quality for 22 days, 9 days and 10 days respectively. The chlorophyll degradation rate was reduced by the DK treatment and the ripening process of green chilies was also reduced by a significant amount.
\end{abstract}

Keywords: Chlorophyll degradation; Dawul kurundu; Edible; Neolestsea involucrate; Mucilaginous

\section{Introduction}

The term post-harvest loss is referring to measurable quantitative and qualitative food loss in the post-harvest system [1]. In developing countries the post-harvest losses are estimated at between $20 \%$ and $50 \%$ in because of the lack of adequate refrigerated facilities and improper handling [2]. Fruits and vegetables are living parts and contain 65\% - 95\% water. Vegetables have a living dynamic system and thus many bio chemical reactions including respiration, transpiration are taken place even after detachment from the parent plant. Since Fruits and vegetables, being living materials, many factors are related to shelf life. There are many methods for preserving fresh produce, such as low temperature storage, controlled atmosphere storage, using anti-microbial agents, irradiation, and modified atmosphere packaging etc. In particular, modified atmosphere packaging (MAP) is very promising, since it is a physical method and easy to practice. Niolitsea involucrate has distributed in india,
Ceylon and Malaysia. It is very common in the most of regions in Sri Lanka up to $4000 \mathrm{ft}$ altitude [3]. The common name is dawul kurundu or Kudu davla. The gum present in Dawul Kurundu is type of polysaccharide, which act as binding agent of some food preparations.

\section{Materials and Methods}

\section{Collection of plant materials}

Leaves of Dawul Kurundu/kudu dawla (Neoletsea involucrate) were collected from Kalutara, Sri Lanka.

\section{Collection of vegetable varieties}

Five types of high respiratory vegetable varieties were collected from the local market and subjected to the study. Those are Gotuloka (Centella asiatica), Mukunuvenna (Alternanthera sessilis), Kankun (Ipomoea aquatic), Leaks (Allium schoenoprasu), Green chili (Capsicum annum) 


\section{Extraction of mucilaginous materials from Dawul Kurundu leaves.}

Fresh matured Dawul kurudu leaves were initially washed and air dried. The extraction of mucilaginous materials was carried out by making the minor modifications to the procedure developed by [4]. One hundred grams of leaves from each mucilaginous material source were taken and steam blanched in $1 \%$ SMS solution for 10 minutes. Just after blanching leaves were washed with cold distilled water. Leaves were mashed manually in $1 \%$ citric acid solutions (leaves: water 1:10 ratio). The Extract was filtered through six layers of muslin cloths. $500 \mathrm{ml}$ of mucilaginous material solutions were prepared by the mucilaginous source.

\section{Properties of prepared mucilaginous solutions}

Determination of the viscosity of the prepared Dawul kurundu mucilaginous solutions: $500 \mathrm{ml}$ of prepared mucilaginous materials solutions were taken in to a beaker. Then the sample was placed on the plate of viscometer. Then, the viscosities were measured at various speeds using $\mathrm{LV}$ spindle. Temperature of the solutions were maintained at $25{ }^{\circ} \mathrm{C}$ using adjustable water bath.

Determination of the film foaming ability of the prepared mucilaginous solution: Initially two petri dished were taken and they were cleaned well and dried well using the hot air oven. Thereafter one petri dish was dipped in mucilaginous material solutions and the other was kept as the control. Then the two dishes were put into the moisture oven for 3 hours. Then, they were taken out and their appearance was compared visually (Transparency and opacity of the dishes).

Preparation of mucilage treated vegetable samples: The application of gum was done by dipping the vegetables in a very dilute mucilaginous solution for 2 minutes and letting thm to drain.

For the Gotukola, Mukunuvenna and Kankun: Initially $30 \mathrm{~g}$ of cleaned green leafy vegetable samples were prepared as bundles and the bundles were dipped in mucilaginous material solutions separately for 30 seconds. Control sample was dipped in distilled water for 30 seconds. Then the excess mucilaginous gum was drained off properly. The coated leaves bundles were dried in a force air dryer at $25^{\circ} \mathrm{C}$ for 30 minutes. Then the dried leaves bundles were packed in polyethylene bags and were sealed and kept under ambient conditions (Temperature $-25^{\circ} \mathrm{C}$ and $85 \% \mathrm{RH}$ ). All polyethylene bags were punctured to get five holes to facilitate the air movement. Thereafter weight loss and keeping quality of each vegetables (how long leafy vegetables were taken to turn yellowish color) were recorded daily. All treatment was triplicated.

For green chilies: Well matured green chili pods at same size were taken and the weight of the samples were recorded, and the same procedure done for green leaves were carried out.

For leeks: Leeks trees at the same size were washed with distilled water and the same procedure done for green leaves were carried out.
Determination of cumulative inedible post-harvest loss of mucilaginous materials coated vegetable samples and control samples

Coated and control vegetables samples were kept under ambient condition $\left(25^{\circ} \mathrm{C}\right.$ and $\left.\mathrm{RH} 85 \%\right)$ while keeping another sample in a refrigerator. Thereafter the inedible part (the parts which has been turned into yellowish colour) of each sample were removed and the cumulative weight of the inedible parts were calculated daily until the whole sample become totally inedible [5].

Determination of the weight losses of the mucilaginous material coated vegetable samples and control samples

Coated and control samples were kept in ambient conditions (30 ${ }^{\circ} \mathrm{C}$ and $\mathrm{RH} 85 \%$ ) while one sample was keeping in the refrigerator. Thereafter weight losses of each sample were recorded daily.

Determination of the chlorophyll degradation of the mucilaginousmaterial coated vegetable samples and control samples

Chlorophyll concentrations were determined as the method of [6].

All the samples were subjected to this procedure daily and the rates of the chlorophyll degradation of each treatment were analyzed and compared with the control sample using the pre-determined equations derived by [7]. This procedure was triplicated for all the samples.

$$
C h a+b=17.76 A^{6466}+7.34 A^{663.6}
$$

Ch: chlorophyll

\section{A: Absorbance}

Analysis of the colour variation of the mucilaginous material coated vegetablr samples and control samples

The colour of each samples were determined by the chromo meter (Konia Minolta, CR - 400 head) and the $\mathrm{L}^{*} \mathrm{a}^{*} \mathrm{~b}^{*}$ colour values were taken.

\section{Results and Discussion}

Determination of the viscosity of the mucilaginous solution prepared from Dawul Kurundu leaves

Viscosity mucilaginous solution prepared from Dawul Kurundu leaveswas $16.5 \mathrm{Cp}$ (30rpm). Dawul kurundu mucilaginous material contain complex polysaccharides which can be formed a hydrocolloid solutions binding with the water molecules of the solution. Amount of the mucilage cells are higher in the dawul kurundu compared to the other plant sources. This polymeric substance are soluble in water and capable of displaying colloidal properties. These mucilaginous materials are the product of the plant metabolic reactions. This mucilaginous material are widely used in the food industry since the capability of mucilaginous materials to enhance the viscosity of a solution. The mucilage 
material are accumulated in between the cell wall and the plasma membrane. Some mucilaginous materials are vacuoles also. Mucilage is in most cases produced in Golgi bodies, from which vesicles filled with polysaccharides move towards the plasma lemma and fuse with it. The mucilage accumulates between the plasma lemma and the cell wall [8].

\section{Determination of weight losses of vegetable samples coated mucilaginous materials.}

When centilla is concerned the highest weight loss was occurred in the control sample which was around 58.1\% $-59.30 \%$ and the lowest loss occurred in the sample kept under refrigerated condition which is around $21 \%$. The weight loss for coated samples was $24.4 \%-27.70 \%$. The appearance of the refrigerated sample and the coated sample was good after the 10 days of storage time since their respiration rate had been reduced. The weight loss is mainly happening due to the respiration and the transpiration of the plant tissues. By the created micro film over the leaves it reduced air movement through the surface while limiting the respiration rate of the Gotukola. As respiration rate is a major indicator of post-harvest produce metabolism, factors which affect this rate are the main consideration in post-harvest preservation of fresh fruit and vegetables. Many technologies for preserving fresh produce involve respiration by manipulating environmental conditions (E.g.: low temperature and modified atmosphere of low $\mathrm{O}_{2}$ and high $\mathrm{CO}_{2}$ ) [2]. When Green Chilli is concerned the highest weight loss was observed in the control sample which was around $32.3 \%$ and the lowest weight loss $(13.3 \%)$ occurred in the samples which kept under refrigerated condition and in the coated sample the loss was around $13.5 \%$. Green chilies were able to keep for 22 days with the coating with very good organoleptic properties. The chili sample kept in the refrigerator was not much edible condition because dark colour patches were occurred on the surface of the chili pods. Surface discolorations and the green colour patches are occurred because of the chilling injuries which are occurred when the chilies are kept under very low temperatures. When Mugunuwenna is concerned the highest weight loss was observed in the control sample which was around $16.6 \%$. The lowest weight loss (5.30\%) was given by the refrigerated sample. The mucilage coated sample also showed low weight loss (9.30\%) compared to the other samples. The keeping qualities of the Mukunuvenna with the mucilaginous coating was not much successful since almost all the leaves had been de greened after 3 days while resulting good organoleptic qualities of the sample kept in the refrigerator. When Leeks is concerned the highest weight loss was given by the control sample which is around $48.6 \%-50 \%$ while the lowest weight loos was given by the refrigerated sample which was around $13.6-15 \%$. The weight loss of the coated samples was $16.6 \%$. When Kankun is concerned the highest weight loss was given by the control sample which is around $11.6 \%-13 \%$. The lowest weight loss was by the refrigerated sample which was around $5 \%$ and weight loss of the coated sample was around $7 \%$. The reason for this consequence is plant mucilage materials capable to form microfilm over the leaf and this film is capable to act as an additional layer over the leaf while partially or fully covering the stomata. Hence evapo transpiration as well as the rate of respiration of produces can be reduced to a great extent. Hydrocolloid films have desirable barrier properties for gas/moisture and good mechanical characteristics have long been known to protect perishable food products from deterioration by retarding dehydration, suppressing respiration, improving textural quality, helping to retain volatile flavor compounds and reducing microbial growth [9].

\section{Evaluation of cumulative inedible percentage of the vegetable samples coated with mucilaginous materials against the control}

When Centilla is concerned the highest inedible percentage is shown by the control sample. The least value was recorded by the sample which was kept in refrigerated condition and the coated sample which were around $11 \%$ and $14.4 \%$ respectively. In here mainly respiration is caused for the turning the colour of the vegetable into yellowish. If the respiration is high it indicated the degradation process also high. Other than that, there is a great impact of the ethylene on vegetable post-harvest degradation process. By this micro film which was created over the produce, minimize the chance to connect ethylene and ethylene receptors while covering the receptors. When Green Chili is concerned the cumulative inedible percentage was highest in the refrigerated sample which was around $28 \%$. The control sample showed $22.6 \%$ inedible percentages while the lowest inedible loss percentage was given by the coated sample which was around $4 \%$ after 22 days of storage time. The reason for this consequence is the chilling injuries which are occurred of some chilling sensitive fruits and vegetables when they are stored at the very low temperatures. The cell wall is damages of the commodity and hence the discolorations are occurred. Because of this discolored parts were occurred at the green chilies which resulting a highest inedible loss of the refrigerated sample. When Mugunuwenna is concerned the lowest inedible loss was given by the refrigerated sample which was around $22 \%$. The coated sample resulted the inedible percentage as $38 \%$. According to the results the best method for keeping Mukunuvenna was the refrigerated condition and coating by mucilaginous materials was not an effective method to extend the post-harvest life of Mukunuvenna. The coating by the plant mucilaginous materials for extension of the shelf life of Mukunuvenna was not successful since almost all the leaves had become de greened when stored for 3 days. When the cumulative inedible portion of Leeks is concerned, the loss was highest in the control sample which is around $25 \%$. The least loss was recorded by the sample which was kept in refrigerated condition and the coated sample was around $9 \%$ respectively. When Kankun is concerned it was observed that there is no significant difference between the mucilaginous coated and non-coated samples of the water spinach (35\%-40\%). The refrigerated sample was given very low inedible percentage compared to the other samples. 
Determination of the chlorophyll degradation rate of the mucilaginous material coated vegetable samples and control samples

The Chlorophyll content in vegetables at the beginning and after three days of treatment were determined. When centilla is concerned the initial chlorophyll content of the vegetable sample was $13.17 \pm 0 \mathrm{mgg}^{-1}$. After three days the initial chlorophyll content of the control sample, refrigerated sample and the coated sample were $1.21 \pm 0.3 \mathrm{mgg}^{-1}, 8.75 \pm 0.1 \mathrm{mgg}^{-1}$ and $8.21 \pm 0.2 \mathrm{mgg}^{-1}$. When Green Chili is concerned the initial chlorophyll content of the sample was $0.31 \pm 0.01 \mathrm{mgg}^{-1}$. After three days the initial chlorophyll content of the control sample, refrigerated sample and the coated sample were $0.15 \pm 0.3 \mathrm{mgg}^{-1}, 0.18 \pm 0.1 \mathrm{mgg}^{-1}$ and $0.26 \pm 0.2 \mathrm{mgg}^{-1}$. When Mugunuwenna is concerned the initial chlorophyll content of sample was $9.5 \pm 0.1 \mathrm{mgg}^{-1}$. After three days the chlorophyll content of the control sample, refrigerated sample and the coated sample were $4.1 \pm 0.2 \mathrm{mgg}^{-1}, 9.4 \pm 0.1 \mathrm{mgg}^{-1}$ and $6.1 \pm 0.2 \mathrm{mgg}^{-1}$. When Allium schoenoprasu is concerned the initial chlorophyll content of the sample was $11.1 \pm 0.1 \mathrm{mgg}^{-1}$. After three days the chlorophyll content of the control sample, refrigerated sample and the coated sample were $4.0 \pm 0.2 \mathrm{mgg}^{-1}, 9.4 \pm 0.1 \mathrm{mgg}^{-1}$ and $6.3 \pm 0.2 \mathrm{mgg}^{-1}$. When water spinach is concerned the initial chlorophyll concentration was $13.5 \pm 0.2$. After three days the chlorophyll content of the control sample, refrigerated sample and the coated sample were $4.1 \pm 0.1 \mathrm{mgg}^{-1}, 9.4 \pm 0.1 \mathrm{mgg}^{-1}$ and $6.1 \pm 0.2 \mathrm{mgg}^{-1}$. Altogether it is clear that the chlorophyll degradation rate was minimum in refrigerated samples. The highest chlorophyll degradation rate was in the control sample. The bleaching of chlorophylls seems to involve lipoxygenase and peroxidase. Orthoefer and Dugan Jr [10]. observed that chlorophyll was bleached in a system which consisted of linoleic acid and lypoxygenase [10]. The yellowing phenomenon, the degradation chlorophylls is involved one or more of following reasons. Pheophytin formation from chlorophyll by organic acids, chlorophyllide formation by chlorophyllase, bleaching reaction of chlorophyll by oxidative reactions, The formation of pheophytin is particularly found in processed food stuffs. Although the chlorophyllase has been thought to catalyze the degradation of chlorophylls, a function for the enzyme in the synthesis of chlrophylls has also been postulated [10]. When the internal $\mathrm{O}_{2}$ composition is lowered respiration causing senescence decreases, preserving the quality of the produce during storage, however, special care has to be taken in order to avoid a very low internal $\mathrm{O}_{2}$ concentration since it can cause anaerobic respiration with consequent ethanol production and off flavour formation [11]. MAP results in the accumulation of $\mathrm{CO}_{2}$ and depletion of $\mathrm{O}_{2}$ around the commodity which increases their storage life [12]. Additionally, the desired atmosphere can reduce the respiration rate, ethylene production and physiological changes [13].

\section{Analysis of $\mathrm{L}^{*} \mathrm{~A}^{*} \mathrm{~B}^{*}$ values of mucilaginous materials coated vegetable samples and control samples}

$L A B$ values of vegetable samples were taken initially and after some days of treatment.

3.5.1 L* $\mathrm{A}^{*} \mathrm{~B}^{*}$ values for centella initially and after 10 days of treatment are shown in Table 1.

When considering the $\mathrm{L}^{*} \mathrm{a}^{*} \mathrm{~b}^{*}$ values of the Table 1 the $\mathrm{L}$ value increases gradually since it indicates the lightness of the sample. At the beginning all the centella samples had the $\mathrm{L}^{*}$ value around 26 - 27. When the Gotukola is kept for days it turns into yellowish colour due to the degreening process of the chlorophylls. The lightness of the sample (L value) is increased gradually. When considering the $a^{*}$ value of the final stage (Turning point into the inedible condition) the largest A value was 60.03 of the control sample and has turned significantly yellowish. Refrigerated samples had the final $L$ value 35.5 and the coated sample showed $\mathrm{L}$ value of 38.1 with the good edible appearance. The a value (-a value) of the sample gradually comes to the positive side (reduce the minus value) since it is indicated the green colour of the sample. When the green color is reduced the - a value comes to the positive.

Table 1: $L^{*} A$ * $B$ * values of centella initially and after ten days.

\begin{tabular}{|c|c|c|c|c|}
\hline Sample & Stage & $\mathbf{L}^{*}$ & $\mathbf{A}^{*}$ & $\mathbf{B}^{*}$ \\
\hline \multirow{2}{*}{ Control } & Initial & $26.1 \pm 0.1$ & $-12.5 \pm 0.1$ & $26.9 \pm 0.05$ \\
\cline { 2 - 5 } & Final & $60.03 \pm 0.05$ & $-6.45 \pm 0.05$ & $50.16 \pm 0.05$ \\
\hline \multirow{2}{*}{ Coated } & Initial & $27.03 \pm 0.05$ & $-12.5 \pm 0.1$ & $27.1 \pm 0$ \\
\cline { 2 - 5 } & Final & $38.1 \pm 0.1$ & $-10.35 \pm 0.05$ & $35.5 \pm 0.1$ \\
\hline \multirow{2}{*}{ Refrigerated } & Initial & $27.3 \pm 0.15$ & $-12.5 \pm 0.1$ & $27.3 \pm 0.15$ \\
\cline { 2 - 5 } & Final & $35.5 \pm 0.11$ & $-10.15 \pm 0.05$ & $32.3 \pm 0.05$ \\
\hline
\end{tabular}

3.5.2 $\mathrm{L}^{*} \mathrm{~A}^{*} \mathrm{~B}^{*}$ values for Green chili initially and after 22 days of treatment are shown in Table 2.

When considering the $L^{*} A^{*} B$ values of the table 2 it is indicated that all the chili samples had the $L$ vales in the range of $26-27$ initially. After 22 days the control sample had become yellowish colour and some green chilies had ripen. The highest $\mathrm{L}$ value has given by the control sample. And the lowest $L$ values has given by the refrigerated sample. In the case of refrigerated sample those green chilies had been subjected to the chilling injuries and there were many discoloured patches of the green chilies. 


\section{Agricultural Research \& Technology: Open Access Journal}

Table 2: $L^{*} A^{*} B^{*}$ values of Green chili initially and after 22 days.

\begin{tabular}{|c|c|c|c|c|}
\hline Sample & Stage & $\mathbf{L}^{*}$ & $\mathbf{A}^{*}$ & $\mathbf{B}^{*}$ \\
\hline \multirow{2}{*}{ Control } & Initial & $26.5 \pm 0.1$ & $-9.56 \pm 0.05$ & $15.23 \pm 0.06$ \\
\cline { 2 - 5 } & Final & $39.3 \pm 0.1$ & $-2.5 \pm 0.1$ & $29.57 \pm 0.32$ \\
\hline \multirow{2}{*}{ Coated } & Initial & $26.46 \pm 0.05$ & $-9.23 \pm 0.05$ & $15.2 \pm 0.1$ \\
\cline { 2 - 5 } & Final & $29.8 \pm 0.05$ & $-4.86 \pm 0.1$ & $20.1 \pm 0.1$ \\
\hline \multirow{2}{*}{ Refrigerated } & Initial & $26.5 \pm 0.2$ & $-9.6 \pm 0.15$ & $15.3 \pm 0.1$ \\
\cline { 2 - 5 } & Final & $11.5 \pm 0.1$ & $-4.9 \pm 0.1$ & $20.2 \pm 0.2$ \\
\hline
\end{tabular}

3.5.3 $\mathrm{L}^{*} \mathrm{~A}^{*} \mathrm{~B}^{*}$ values for Alternanthera sessilis initially and after 3 days of treatment are shown in Table 3.

According to the Table 3 the highest $\mathrm{L}^{*}$ value was for control sample and the lowest $L^{*}$ value was around $42.2 \pm 0.2$ which was the refrigerated sample. When considering the $A^{*}$ values the lowest $A^{*}$ value was given by the refrigerated sample which was around $-10.5 \pm 0.1$ while the highest $A^{*}$ value was given by the control sample around $-6.1 \pm 0.1$. According to the $B^{*}$ values the highest
$\mathrm{B}^{*}$ value was given by the control sample around $46.3 \pm 0.2$ while lowest $\mathrm{B}^{*}$ value was indicated by the refrigerated sample around $30.2 \pm 0.0$ value. The lightness of the control sample had been increased rapidly. According to the $A^{*}$ values the highest greenness value $\left(A^{*}\right)$ was given by the refrigerated sample. According to the colour measurement values the best sample was the refrigerated sample and the coating with mucilaginous material was not given good results into satisfactory level.

Table 3: $L^{*} A^{*} B^{*}$ values of Alternanthera sessilis initially and after 3 days.

\begin{tabular}{|c|c|c|c|c|}
\hline Sample & Stage & $\mathbf{L}^{*}$ & $\mathbf{A}^{*}$ & $\mathbf{B}^{*}$ \\
\hline \multirow{3}{*}{ Control } & Initial & $32.0 \pm 0.5$ & $-12.4 \pm 0.2$ & $13.5 \pm 0.1$ \\
\cline { 2 - 5 } & Final & $51.8 \pm 0.3$ & $-6.1 \pm 0.1$ & $16.3 \pm 0.2$ \\
\hline \multirow{2}{*}{ Coated } & Initial & $32.1 \pm 0.1$ & $-12.6 \pm 0.1$ & $3.3 \pm 0.15$ \\
\cline { 2 - 5 } & Final & $47.2 \pm 0.0$ & $-7.0 \pm 0.05$ & $13.5 \pm 0.1$ \\
\hline \multirow{2}{*}{ Refrigerated } & Initial & $33.6 \pm 0.0$ & $-12.5 \pm 0.1$ & $30.2 \pm 0.0$ \\
\cline { 2 - 5 } & Final & $42.2 \pm 0.2$ & $-10.5 \pm 0.1$ & 0.2 \\
\hline
\end{tabular}

3.5.4 L* A* $\mathrm{B}^{*}$ values for Allium schoenoprasu initially and after 3 days of treatment are shown in Table 4 .

According to Table 4 it is indicated that the initial $\mathrm{L}^{*}$ values of the leaks samples were around 36.5. The highest $L^{*}$ value of after the 9 days was 60.10 from the control sample and the lowest $L^{*}$ value was around $40.36 \pm 0.15$ which was the refrigerated sample. The coated sample was given lower $L^{*}$ value which was closer to the refrigerated sample. When considering the $A^{*}$ values the lowest $A^{*}$ value was given by the refrigerated sample which was around $-7.1 \pm 0.05$ while the highest $A^{*}$ value was given by the control sample. According to the $\mathrm{B}^{*}$ values the highest $\mathrm{B}^{*}$ value was given by the control sample around $34.2 \pm 0.2$ while lowest $\mathrm{B}^{*}$ value was indicated by the refrigerated sample around $18.4 \pm$ 0.1 value.

Table 4: $L^{*} A^{*} B^{*}$ values ofAllium schoenoprasu initially and after 9 days.

\begin{tabular}{|c|c|c|c|c|}
\hline Sample & Stage & $\mathbf{L}^{*}$ & $\mathbf{A}^{*}$ & $\mathbf{B}^{*}$ \\
\hline \multirow{2}{*}{ Control } & Initial & $36.7 \pm 0.5$ & $-8.2 \pm 0.1$ & $10.2 \pm 0.1$ \\
\cline { 2 - 5 } & Final & $60.1 \pm 0.1$ & $-5.3 \pm 0.1$ & $34.2 \pm 0.2$ \\
\hline \multirow{2}{*}{ Coated } & Initial & $36.7 \pm 0.1$ & $-8.0 \pm 0.05$ & $10.36 \pm 0.3$ \\
\cline { 2 - 5 } & Final & $45.5 \pm 0.1$ & $-6.8 \pm 0.0$ & $24.8 \pm 0.2$ \\
\hline \multirow{2}{*}{ Refrigerated } & Initial & $36.2 \pm 0.6$ & $-8.2 \pm 0.05$ & $10.5 \pm 0.1$ \\
\cline { 2 - 5 } & Final & $40.36 \pm 0.15$ & $-7.1 \pm 0.05$ & $18.4 \pm 0.1$ \\
\hline
\end{tabular}

3.5.5 L* $\mathrm{A}^{*} \mathrm{~B}^{*}$ values for water spinach initially and after 3 days of treatment are shown in Table 5.

According to the Table 5, it is indicated that all the samples had the $L^{*}$ vales around 30.1 . The highest $L$ values was given by the control sample which was around $53.3 \pm 0.05$. The lowest $L^{*}$ value was given from the refrigerated sample which was around $38.1 \pm$ 0.1 . When considering $A^{*}$ value the control samples gave $6.8 \pm 0.11$ as the lowest $L^{*}$ values. When considering the $B^{*}$ values the lowest $B^{*}$ value has given by the refrigerated samples around $22.4 \pm 0.05$. 


\section{Agricultural Research \& Technology: Open Access Journal}

Table 5: $L^{*} A^{*} B^{*}$ values of water spinach initially and after 3 days of treatment.

\begin{tabular}{|c|c|c|c|c|}
\hline Sample & Stage & $\mathbf{L}^{*}$ & $\mathbf{A}^{*}$ & $\mathbf{B}^{*}$ \\
\hline \multirow{3}{*}{ Control } & Initial & $30.1 \pm 0.05$ & $-10.2 \pm 0.2$ & $15.1 \pm 0.05$ \\
\cline { 2 - 5 } & Final & $53.3 \pm 0.05$ & $-6.4 \pm 0.1$ & $45.5 \pm 0.2$ \\
\hline \multirow{3}{*}{ Coated } & Initial & $30.1 \pm 0.05$ & $-10.2 \pm \pm 0.2$ & $16.1 \pm 0.05$ \\
\cline { 2 - 5 } & Final & $46 \pm 0.5$ & $-7.7 \pm .1$ & $42 \pm 0.2$ \\
\cline { 2 - 5 } & Final & $51.6 \pm 0.2$ & $-6.7 \pm 0.1$ & $45.5 \pm 0.1$ \\
\hline \multirow{2}{*}{ Refrigerated } & Initial & $30.1 \pm 0.1$ & $-10 \pm 0.05$ & $15.4 \pm 0.1$ \\
\cline { 2 - 5 } & Final & $38.1 \pm 0.1$ & $-8.4 \pm 0.1$ & $22.4 \pm 0.5$ \\
\hline
\end{tabular}

The colour is very critical for any vegetable for which is directly affect to the consumer acceptance of the commodity. In green vegetables, the senescence process usually leads to a yellow colouration of the tissue, because of the degradation of chlorophylls and the formation of pheophytins. The maintenance high relative humidity, combined with atmospheres lowered in $\mathrm{O}_{2}$ and moderately enriched in $\mathrm{CO}_{2}$, are shown to delay chlorophylls degradation [14].

\section{Conclusion}

The coating of vegetables by plant mucilaginous material can be applied successfully for some vegetable varieties. By this coating a micro film is formed over the vegetables creating a barrier for the moisture and air migration through the surface while lowering the rate of respiration and evapo- transpiration of the vegetable. The weight loss was reduce in great extent by the Dawul Kurundu coating since this micro film act as an additional layer over the leaf surface while covering the stomata holes. Hence the deterioration process is reduced resulting a long post-harvest life. This mucilage coating can be successfully applied for the Gotukola, green chilies and for the leeks and they could be kept with good quality for 10 days, 9 days and 22 days respectively. Although the dawul kurudu having the considerable moisture barrier coating properties that was not enough to retard the action of the ethylene in the case of Mukunuvenna and kankun.

\section{References}

1. Lucia MD, Assennato D (1994) Agricultural engineering in development: Post harvest operations and management of food grains. Food and Agriculture Organization of United Nations, USA.

2. Lee L, Arult J, Lenckit R, Castaigne F (1995) A Review on Modified Atmosphere Packaging and Preservation of Fresh Fruits and Vegetables: Physiological Basis and Practical Aspects-Part I. Packaging technology and science 9(1): 1-17.
3. Jayaweera DMA (1982) Medicinal plants used in Ceylon, Part 3 . National science council of Sri Lanka, Colombo 13(1982): 1-52.

4. Kasunmala IGG, Navarathne SB, Wickramasinghe I (2017) Extraction and characterization of mucilaginous material from Dawul Kurundu Leaves (Neolitsea involucrate) and Godapara fruits (Dillenia retusa).

5. Dell Valle JM, Godoy C, Asencio M, Aguilera JM (2004) Recovery of Natural Antioxidants from Boldo (Peumus boldus M.) Using Conventional Solvents and Supercritical $\mathrm{CO}_{2}$ Extraction. Food Res Int 37: 695 .

6. Sumanta N, Haque CI, Nishika J Suprakash R (1989) Determination of accurate extinction coefficients and simultaneous equations for assaying chlorophylls a and $\mathrm{b}$ extracted with four different solvents: verification of the concentration of chlorophyll standards by atomic absorption spectroscopy.

7. Porra RJ, Thompson WA, Kriedemann PE (1989) Dioision of Plant Industry, Commonwealth Scientific and Industrial Research Organization. Canberra Biochimica et Biophysica Acta 975: 384-394.

8. Fahn A (1979) Secretory tissues in plants. New York: Academic Press, USA.

9. HershkoV, Nussinovitch A (1998) Food hydrocolloids 12(2): 195-202.

10. Yamauchi N, Minamide T (1985) Chlorophyll degradation by peroxidase in parsley leaves.

11. Kays SJ, Paull RE (2004) Stress in harvested products. In: Postharvest biology. Exon Press, Athens, pp. 355-414.

12. Karder AA, Zagory D, Kerbel EL (1989) Modified atmospheric packaging of Fruits and Vegeetables. CRC Critical Reviews in Food Science and Nutrition 28: 1-30.

13. Kader AA (1992) Postharvest biology and technology: an overview. In: Kader AA (Eds.) Postharvest technology of horticultural crops. University of California, UK, p. 15-20.

14. Artes F, Gomez PA, Artes-Hernandez F (2007) Physical, physiological and microbial deterioration of minimally fresh processed fruits and vegetables. Food Science and Technology International 13: 177-188. 
This work is licensed under Creative Commons Attribution 4.0 License

DOI: 10.19080/ARTOAJ.2018.16.556005

\section{Your next submission with Juniper Publishers} will reach you the below assets

- Quality Editorial service

- Swift Peer Review

- Reprints availability

- E-prints Service

- Manuscript Podcast for convenient understanding

- Global attainment for your research

- Manuscript accessibility in different formats ( Pdf, E-pub, Full Text, Audio)

- Unceasing customer service

Track the below URL for one-step submission https://juniperpublishers.com/online-submission.php 